\title{
Do Nearctic migrant birds compete with residents at army ant raids? A geographic and seasonal analysis
}

Author(s): Sean O'Donnell, Anjali Kumar, and Corina J. Logan

Source: The Wilson Journal of Ornithology, 126(3):474-487.

Published By: The Wilson Ornithological Society

DOI: http://dx.doi.org/10.1676/13-109.1

URL: http://www.bioone.org/doi/full/10.1676/13-109.1

BioOne (www.bioone.org) is a nonprofit, online aggregation of core research in the biological, ecological, and environmental sciences. BioOne provides a sustainable online platform for over 170 journals and books published by nonprofit societies, associations, museums, institutions, and presses.

Your use of this PDF, the BioOne Web site, and all posted and associated content indicates your acceptance of BioOne's Terms of Use, available at www.bioone.org/page/ terms of use.

Usage of BioOne content is strictly limited to personal, educational, and non-commercial use. Commercial inquiries or rights and permissions requests should be directed to the individual publisher as copyright holder. 


\title{
DO NEARCTIC MIGRANT BIRDS COMPETE WITH RESIDENTS AT ARMY ANT RAIDS? A GEOGRAPHIC AND SEASONAL ANALYSIS
}

\author{
SEAN O’DONNELL,${ }^{1,4}$ ANJALI KUMAR, ${ }^{2}$ AND CORINA J. LOGAN ${ }^{3}$
}

\begin{abstract}
Army ant swarm raids in Neotropical montane forest are attended by diverse flocks of foraging birds that can include residents year-round and overwintering Nearctic migrants. We asked whether migrants and residents affect each other's ability to forage at army ant raids. We quantified variation in raid attendance by three guilds of birds: wintering migrants, regular and obligate raid attending residents (ant-following residents), and facultative raid attending residents. To test whether wintering migrants and residents were negatively associated at raids, we collected data on raid attendance in four adjacent life zones in the Tilarán Mountains of Costa Rica and in different seasons (when migrants were present and absent). We first compared the guilds' raid attendance among life zones. There was little geographic overlap of migrants and ant-following residents at raids, and raid attendance frequencies were strongly correlated with the estimated local abundances of these bird guilds in each life zone. We then analyzed resident bird flock size and species makeup in the life zones where migrants attended raids most often (Premontane and Lower Montane Wet forests). If migrants affected raid attendance by facultative resident birds, we expected resident numbers or species richness at raids to decrease with migrant presence. Resident flock size and species richness did not differ between times of year with and without migrants, and species identities differed little between seasons. Furthermore, resident flock composition in migrant presence season was similar at raids with and without migrants. We conclude migrants had no measurable effect on resident bird army ant exploitation. Migrants were smaller on average and less likely than residents to capture prey from the ground at raids. These body size and foraging substrate differences between residents and migrants may mitigate inter-guild competition for food at raids. Received 11 July 2013. Accepted 28 January 2014.
\end{abstract}

Key words: Costa Rica, Eciton burchellii, montane forest, Neotropics.

Nearctic migrant birds (henceforth migrants), species that breed in North America and overwinter in Neotropical or subtropical habitats, face an array of opportunities and challenges when they arrive at their wintering grounds (Salewski et al. 2003). Wintering migrants must integrate themselves into tropical bird communities, potentially facing competition with residents for resources such as space and food (Leisler 1992, Salewski et al. 2007). Conversely, the arrival of substantial numbers of migrants may deplete food and other resources, negatively affecting residents' foraging. Studies at stopover sites and migrant wintering habitats have compared resident behavior and foraging success in the presence and absence of migrants. In some cases, resident changes in foraging behavior, habitat use, or prey selection when migrants arrive suggest competition with migrants (Chipley 1976, Rabol 1987, Kirk and Curall 1994, Jedlicka et al. 2006, Bensusan et al. 2011). In other cases, migrants had

\footnotetext{
${ }^{1}$ Department of Biodiversity, Earth and Environmental Science, Drexel University, Philadelphia, PA 19104, USA.

${ }^{2}$ Massachusetts Institute of Technology, 265 Massachusetts Avenue, Cambridge, MA 02139, USA.

${ }^{3}$ Sage Center for the Study of the Mind, University of California, Santa Barbara, Santa Barbara, CA 93106, USA.

${ }^{4}$ Corresponding author; e-mail: so356@drexel.edu
}

no measurable effect on residents (Johnson et al. 2006, Randler 2013).

Although many migrant passerine birds occupy similar abiotic niches in their breeding and wintering ranges, birds wintering in the Neotropics can gain access to novel food resources that are unavailable in North America (Leisler 1992, Nakazawa et al. 2004). Army ant swarm raids are an excellent example. Some army ant species (Eciton burchellii and Labidus praedator) forage over the forest floor in massive swarm raids (Kronauer 2009). Birds, including migrants, attend the swarm raids. Attending birds feed on arthropods and small vertebrates that flee the advancing ants (Willis and Oniki 1978, Wrege et al. 2005). Foraging at army ant raids is a highly profitable strategy for tropical insectivores (Willis 1972, Harper 1989, Zimmer and Isler 2003, Meisel 2004). Migrants attend raids in the company of residents (Willis 1966, Roberts et al. 2000, O'Donnell et al. 2010). The goal of our study was to assess whether residents and migrants affect each other's abilities to exploit army ant swarms. We did this by measuring geographic variation in raid attendance by residents and migrants in different life zones along an elevational transect, and by comparing raid attendance at times of year when migrants were present and absent. 
Army ant exploitation varies in importance among resident bird species. Some Neotropical birds specialize as army ant raid attendants, mainly species in the antbird family (Thamnophilidae). These birds do not hold feeding territories and track mobile army ant colonies as the ants emigrate through the forest (Brumfield et al. 2007, Moyle et al. 2009). We refer to these species as " "ant-following residents."' There is also a diverse array of facultative raid attending resident birds. Facultative resident species vary in frequency of visits to ant swarms, and some species perform behaviors that enhance army ant exploitation, such as visiting army ant nest sites (bivouac checking; O'Donnell et al. 2010, 2012). Some migrants attend raids over wide geographic ranges and at relatively high frequencies, which suggests that army ant exploitation is an important overwinter foraging tactic for these species (Willis 1966, 1984; Hardy 1974; Greene et al. 1984; Coates-Estrada and Estrada 1989; Roberts et al. 2000; Meisel 2004; Rios et al. 2008).

We used two approaches to test for potential interactions among residents and migrants at army ant raids. First, we sampled geographic variation in raid attendance. Our montane study site spanned four Holdridge life zones with distinct avifaunas (Monteverde, Costa Rica: Young et al. 1998, Young and MacDonald 2000, Jankowski et al. 2009). Diurnal army ant swarm raids occur at relatively high rates throughout our sampling area (O’Donnell et al. 2011). We grouped bird species that attended raids into three guilds: migrants, antfollowing residents, and facultative residents. We asked whether use of army ant raids, as indicated by species richness and numbers of birds, was negatively associated between these guilds across life zones. We used previously collected mist net capture data as an index of relative abundances of these bird guilds among life zones. We used these data to estimate the effects of lifezone variation in abundance on frequencies of raid attendance (Young et al. 1998).

Interference competition is an important determinant of raid attending flock composition in lowland tropical forests: aggression by antfollowing residents can reduce or prevent raid attendance by other birds (Willson 2004, Brumfield et al. 2007, Touchton and Smith 2011). During two field seasons we recorded data on aggressive interactions among birds at raids. We asked whether migrants and residents showed inter-guild aggression.
Finally, in the life zones where migrants were most abundant at raids, we compared resident bird raid attendance in the presence and absence of migrants. If migrants reduced raid profitability for resident birds, we expected raid attendance by facultative residents to be inhibited in the presence of migrants. We tested whether resident bird flock composition (species richness, species identities, and numbers of birds) differed between seasons when migrants were present and absent. We also compared resident flocks at raids with and without migrants during the migrant presence season. To assess potential for overlap in resource use between migrants and residents, we tested whether body size and substrate used while foraging at raids differed between the guilds. Species-typical body size and foraging behavior are frequently used as proxies for resource use in avian ecology studies (reviewed by Sridhar et al. 2012).

\section{METHODS}

\section{Study Site, Sampling Dates, and Seasons}

We collected data in forests in the vicinity of Monteverde, Puntarenas Province, Costa Rica (Tilarán Mountain range; $10^{\circ} 18^{\prime} \mathrm{N}, 84^{\circ} 48^{\prime} \mathrm{W}$; Guindon 1997, Harvey 2000). We observed birds at 72 swarm raids, 62 of Eciton burchellii and 10 of Labidus species. We sampled four elevationally adjacent Holdridge life zones (Holdridge 1966, Haber 2000). The life zones sampled, elevation ranges of observations, and raid sampling effort were: Premontane Wet Forest (PMWF, Pacific slope, 1,170-1,470 $\mathrm{m}$ above sea level; 29 raids in migrant presence season plus 19 raids in migrant absence season), Lower Montane Wet Forest (LMWF, Pacific slope, 1,490-1,550 m asl; 10 raids), Lower Montane Rain Forest (LMRF, Atlantic slope, 1,350-1,680 m asl; two raids), and Premontane Rain Forest (PMRF, Atlantic slope, $985-1,250 \mathrm{~m}$ asl; 12 raids).

We observed birds at raids during times of the year when migrants occur in the Monteverde area and during periods when migrants are breeding in North America (Stiles and Skutch 1989, Garrigues and Dean 2007). We separated our data set into two seasons for analyses: migrant presence (OctApr) and migrant absence (Jul-Sept). Data were collected during seven separate observation periods that collectively spanned much of the year: 11 January-4 March 2005, 2 July-11 December 2005, 19 December 2007-1 January 2008, 7-10 
April 2008, 7-19 January 2012, 20-27 July 2012, and 8-21 April 2013. Sampling Bird Flock Composition and Behavior
at Army Ant Raids

We observed a maximum of two raids per day (raids observed on the same day were from different army ant colonies), and we alternated sampling dates among life zones whenever possible. Each swarm observation was treated as an independent data point (Coates-Estrada and Estrada 1989, Kumar and O'Donnell 2007). We made all observations during daylight hours; observation session start times ranged from 0900-1600 local time.

We detected army ant foraging raids by encountering army ant raid fronts, encountering columns of army ants, or observing birds active at or near ground level in the forest. We walked to the swarm front, and if birds were present we positioned ourselves within $5 \mathrm{~m}$ of the ant swarm at a location with unobstructed viewing of the raid front. Observations lasted for $1 \mathrm{hr}$ except when raid activity ceased, when heavy rainfall began, or when the ants traversed impassable terrain. We collected the following data at the army ant swarms, based on the methods of Coates-Estrada and Estrada (1989): (1) Start and end time to the nearest min. (2) Life zone based on geographic location (GPS coordinates) of the raid, referring to previously published life zone maps of the area (Young et al. 1998). (3) Species identity of each raid-attending bird. We identified birds to species based on plumage, behavior, relative body size, geographic range, and vocalizations (Stiles and Skutch 1989, Garrigues and Dean 2007). Only birds seen pursuing or consuming prey fleeing from the ants were counted as raid attendants. We noted whenever the number of individuals of a species changed, and we used the maximum number of individuals seen at the same time as a conservative estimate of the number of birds from each species. (4) The foraging substrate used by raid attendant birds in three broad categories: vegetation- birds perched on branches or trunks, or sallied to catch prey, but did not land on the ground; pounce- birds at least sometimes landed on the ground to capture prey but returned to perches on vegetation after moving $<1 \mathrm{~m}$ across the ground; ground- birds at least sometimes walked or hopped on the ground in pursuit of prey, moving a distance of at least $1 \mathrm{~m}$ across the ground. Birds were categorized as residents or migrants, and some residents were further classified as ant-followers (Swartz 2001, Zimmer and Isler 2003, Meisel 2004, Brumfield et al. 2007). We used species' mean weight in grams as an index of body size with weight data taken from Stiles and Skutch (1989).

\section{Aggressive Interactions at Army Ant Raids}

We noted interspecific and intraspecific aggressive interactions among the attending birds during the December 2007-January 2008 and the January 2012 field seasons. We recorded every incidence of displacement, defined as an aggressor flying to within $0.5 \mathrm{~m}$ of a target bird, with the target bird flying or running off at least $1 \mathrm{~m}$ before stopping. We noted whether target birds moved but remained at the army ant raid, or apparently departed the area.

\section{Statistical Analyses}

Life Zone Differences in Raid Attendance by Guilds.-We analyzed two aspects of bird flock composition at each raid: the number of species per guild and the number of individuals per guild. We used General Linear Models (GLM) to test life zone differences in flock composition. All GLM analyses were performed with SPSS version 20 software (IBM Inc. 2011). In the statistical models, we tested for life zone differences in mean numbers of species and individuals in each bird guild (migrants, ant-following residents, and facultative residents). We used Spearman rank correlation (for non-normal data) to test whether the numbers of migrants and ant-following residents at raids, and numbers of migrants and facultative residents at raids, were associated.

Correlations of Raid Attendance and Local Abundance.-We used mist net captures from previously published studies in the four Monteverde life zones we sampled as an index of each species' local abundance (Young et al. 1998). Mist net capture data have inherent biases for estimating bird population densities, but some of the interspecific biases should be minimal when comparing densities of the same set of species across adjacent life zones (Remsen and Good 1996). We used the normalized mist net capture frequency (captures/1,000 birds for each species) in each life zone for the species we observed at raids. The guild density index was the sum of the normalized mist net capture frequencies for all species in the guild we observed at raids. We used Pearson correlation to test whether the mean number of birds per raid and the density index 
were correlated among life zones for migrants and for ant-following residents.

Comparisons of Raids With and Without Migrants.-These analyses were restricted to raids observed in the PMWF life zone, the life zone with the highest frequency of migrants at raids. We used GLM to test whether the mean number of resident birds at raids differed between migrant presence and absence seasons, and between raids with and without migrants.

We used software for comparing the numbers of species between ecological samples to test whether species richness of residents at raids varied with migrant presence (Estimates software; Colwell 2009). We used analytically-computed species accumulation curves (Mao Tau statistic) with 95\% confidence intervals to assess whether resident species' numbers at raids differed when migrants were present versus absent. If the resident species richness in a sample (e.g., raids with migrants) was outside the $95 \%$ CI for another sample (e.g., raids without migrants), we concluded the samples differed significantly in resident species richness.

To test whether the species identities of resident birds at raids differed in the presence and absence of migrants, we used the Chao-Sorensen species overlap statistic (Estimates 8.2). In our test the Chao-Sorensen statistic estimates the probability a randomly selected bird in one season's sample would be from a species that attended raids in both seasons.

Tests for Guild Differences in Size and Foraging Substrate.-We used only data from Pacific slope raids during the migrant presence season for these analyses, and we treated each attending bird as a data point for both analyses. Each bird was assigned its species mean body weight in grams as an index of size (Stiles and Skutch 1989) and its species-typical foraging substrate based on our observations. First, we tested for guild (migrant vs. facultative resident) differences in body size using GLM. We then used Chi-squared analysis of the frequency of birds that used the three foraging substrates (ground, pounce, or vegetation) in each guild (migrant vs. facultative resident).

\section{RESULTS}

Flock Composition during the Migrant Presence Season

We collected data at 53 army ant raids in the migrant presence season. We observed 62 species of birds attending these raids. Eleven species were Nearctic migrants and five species were ant followers (Table 1); the remaining species were facultative resident raid attendants. Residents were present at all raids with birds in attendance. The total number of birds at a raid ranged from 1 to 25 (mean \pm SE: $8.06 \pm 0.79$ ), and the number of species at a raid ranged from 1 to 17 (mean \pm SE: $5.09 \pm 0.47)$. The number of migrant individuals at a raid ranged from 0 to 7 (mean \pm SE: $0.77 \pm 0.17$ ), and the number of migrant species at a raid ranged from 0 to 6 (mean \pm SE: $0.72 \pm 0.15$ ). The numbers of migrants and facultative residents at raids were positively associated (Spearman correlation, $r_{s}=0.34, P$ $=0.014, \mathrm{df}=51$ ), while the numbers of migrants and ant-following residents at raids were negatively associated $\left(r_{s}=-0.36, P=0.009, \mathrm{df}=\right.$ 51).

\section{Life Zone Differences in Raid Attendance among Guilds}

Facultative residents were present at raids in all life zones, although many species were restricted to the Pacific or Atlantic slope (Table 1; Fig. 1A). The number of facultative resident birds at a raid did not vary significantly among life zones (Fig. $1 \mathrm{~A} ; F_{3,49}=0.95, P=0.43$ ), and the species richness of facultative resident birds at a raid did not vary significantly among life zones $\left(F_{3,49}=\right.$ $1.65, P=0.19$ ).

In contrast to the geographic constancy of facultative resident raid attendance, the number of migrant individuals at a raid differed significantly among life zones (Fig. 1A; $F_{3,49}=2.92, P=$ 0.04 ), and the number of migrant species at a raid varied significantly among life zones $\left(F_{3,49}=\right.$ $2.86, P=0.049)$. Life zones also differed in the number of ant follower individuals at a raid (Fig. $1 \mathrm{~A} ; F_{3,49}=14.86, P<0.001$ ) and in the number of ant follower species at a raid $\left(F_{3,49}\right.$ $=16.76, P<0.001)$. Ant-following residents and migrants were largely separated among life zones. Ant follower raid attendance was lowest (zero) in the Pacific Slope PMWF life zone, and increased moving toward and onto the Atlantic Slope. Conversely, migrant raid attendance was highest in PMWF and decreased moving onto the Atlantic slope (Table 1; Fig. 1A).

\section{Estimates of Life Zone Variation in Guild Density}

The mean mist-net capture frequency of the 11 migrant species we observed at raids varied 
TABLE 1. Species of birds from three guilds (ant-following residents, migrants, and facultative residents) observed attending army ant swarm raids in montane forests near Monteverde, Costa Rica. Species are listed in descending order of body size within guilds (species mean weight, g). All ant-following residents and migrants are listed; only the most frequently observed facultative resident species are listed (those with a total of at least nine individuals seen at raids). For each bird species, we indicate typical foraging substrate, average species body weight, and the number and percent of raids attended on each slope of the continental divide $(n=39$ Pacific slope raids, PMWF and LMWF life zones; $n=14$ Atlantic slope raids, LMRF and PMRF life zones).

\begin{tabular}{|c|c|c|c|c|}
\hline $\begin{array}{c}\text { GUILD } \\
\text { Species common name, scientific name }\end{array}$ & $\begin{array}{l}\text { Foraging } \\
\text { substrate }\end{array}$ & Body weight, g & $\begin{array}{l}\text { Percent and (Number) } \\
\text { of Atlantic slope } \\
\text { raids attended }\end{array}$ & $\begin{array}{l}\text { Percent and (Number) } \\
\text { of Pacific slope } \\
\text { raids attended }\end{array}$ \\
\hline \multicolumn{5}{|l|}{ ANT-FOLLOWING RESIDENTS } \\
\hline Ocellated Antbird, Phaenostictus mcleannani & Pounce & 55 & $21 \%(3)$ & 0 \\
\hline Immaculate Antbird, Myrmeciza immaculata & Pounce & 40 & $86 \%(12)$ & $5 \%(2)$ \\
\hline Bicolored Antbird, Gymnopithys leucaspis & Pounce & 30 & $14 \%(2)$ & 0 \\
\hline Dull-mantled Antbird, Myrmeciza laemosticta & Pounce & 25 & $7 \%(1)$ & 0 \\
\hline Spotted Antbird, Hylophylax naevioides & Pounce & 18 & $14 \%(2)$ & 0 \\
\hline ANT-FOLLOWING RESIDENTS TOTAL & - & - & $86 \%(12)$ & $5 \%(2)$ \\
\hline \multicolumn{5}{|l|}{ MIGRANTS } \\
\hline Wood Thrush, Hylocichla mustelina & Ground & 48 & 0 & $18 \%(7)$ \\
\hline Swainson's Thrush, Catharus ustulatus & Ground & 28 & 0 & $13 \%(5)$ \\
\hline Ovenbird, Seiurus aurocapilla & Ground & 18 & 0 & $3 \%(1)$ \\
\hline Kentucky Warbler, Oporornis formosus & Ground & 13 & $7 \%(1)$ & $26 \%(10)$ \\
\hline Philadelphia Vireo, Vireo philadelphicus & Vegetation & 11.5 & 0 & $3 \%(1)$ \\
\hline Black-and-white Warbler, Mniotilta varia & Vegetation & 11 & $7 \%(1)$ & $5 \%(2)$ \\
\hline Canada Warbler, Wilsonia canadensis & Vegetation & 10.5 & 0 & $3 \%(1)$ \\
\hline Black-throated-green Warbler, Dendroica virens & Vegetation & 9 & 0 & $3 \%(1)$ \\
\hline Chestnut-sided Warbler, Dendroica pensylvanica & Vegetation & 9 & 0 & $3 \%(1)$ \\
\hline Golden-winged Warbler, Vermivora chrysoptera & Vegetation & 8.5 & 0 & $3 \%(1)$ \\
\hline Wilson's Warbler, Wilsonia pusilla & Vegetation & 7 & 0 & $13 \%(5)$ \\
\hline MIGRANTS TOTAL & - & - & $14 \%(2)$ & $56 \%(22)$ \\
\hline \multicolumn{5}{|l|}{ FACULTATIVE RESIDENTS } \\
\hline Brown Jay, Cyanocorax morio & Pounce & 235 & $0(0)$ & $36 \%(14)$ \\
\hline Blue-crowned Motmot, Momotus momota & Pounce & 120 & $0(0)$ & $38 \%(15)$ \\
\hline Azure-hooded Jay, Cyanolyca cucullata & Pounce & 88 & $14 \%(2)$ & $8 \%(3)$ \\
\hline Ruddy Woodcreeper, Dendrocincla homochroa & Pounce & 44 & $14 \%(2)$ & $13 \%(5)$ \\
\hline White-eared Ground Sparrow, Melzone leucotis & Ground & 43 & $0(0)$ & $46 \%(18)$ \\
\hline Slaty-Backed Nightingale Thrush, Catharus fuscater & Ground & 35 & $64 \%(9)$ & $13 \%(5)$ \\
\hline \multicolumn{5}{|l|}{ Orange-billed Nightingale Thrush, Catharus } \\
\hline aurantiirostris & Ground & 27 & $0(0)$ & $67 \%(26)$ \\
\hline Rufous-and-white Wren, Thryothorus rufalbus & Pounce & 25 & $0(0)$ & $26 \%(10)$ \\
\hline Rufous-capped Warbler, Basileuterus rufifrons & Vegetation & 11.5 & $0(0)$ & $26 \%(10)$ \\
\hline Three-striped Warbler, Basileuterus tristriatus & Vegetation & 12 & $0(0)$ & $13 \%(5)$ \\
\hline Golden-crowned Warbler, Basileuterus culicivorus & Vegetation & 10.5 & $29 \%(4)$ & $13 \%(5)$ \\
\hline Slate-throated Whitestart, Myioborus miniatus & Vegetation & 10 & $7 \%(1)$ & $15 \%(6)$ \\
\hline FACULTATIVE RESIDENTS TOTAL & - & - & $100 \%(14)$ & $100 \%(39)$ \\
\hline
\end{tabular}

among life zones (Fig. 1B; Young et al. 1998). In accordance with their frequency at army ant raids, these species were captured most often in PMWF, at intermediate rates in LMWF, and least often on the Atlantic slope. In contrast, antfollowing residents were captured only in PMRF on the Atlantic slope. Life zone-mean numbers of migrants and ant-following residents at raids were significantly positively correlated with their mist net-estimated abundances taken from Young et al. (1998) (migrants: $r_{s}=0.99, P=0.004, n$ $=4$; ant-following residents: $r_{s}=0.98, P=$ $0.02, n=4)$.

\section{Aggressive Interactions at Raids}

We collected data on aggressive interactions among attending birds at 11 army ant raids during the December 2007-January 2008 field season. 

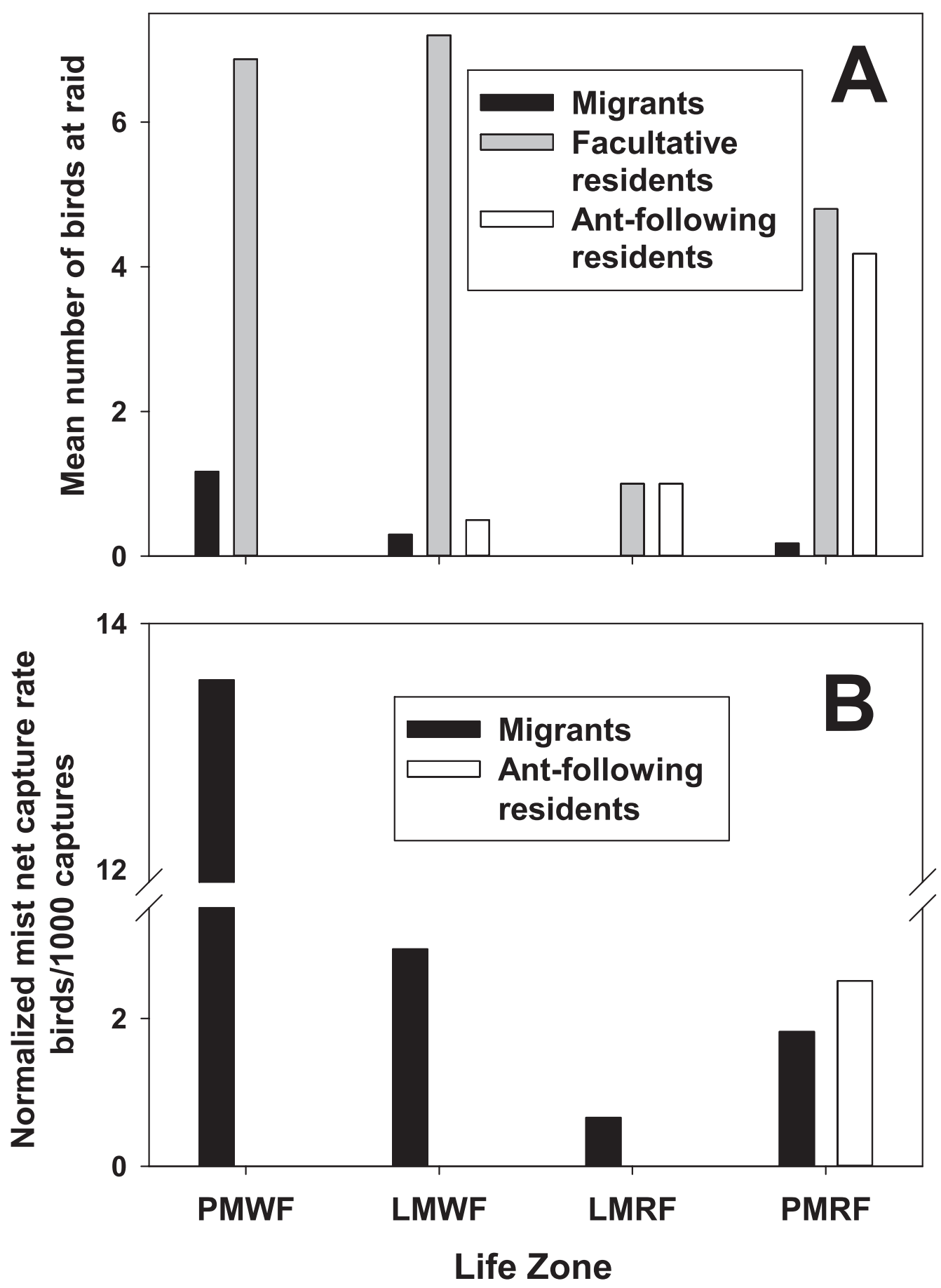

FIG. 1. Bar graphs showing: A) mean numbers of birds from three guilds (ant-following residents, facultative residents, and migrants) observed at army ant raids in four life zones; B) normalized mist net capture frequencies of migrants and ant followers from four life zones. Data are from four adjacent life zones in Costa Rican montane forests. Life zones are arranged in approximate west-to-east order from the Pacific slope to the Atlantic slope. Life zone abbreviations: Premontane Wet Forest (PMWF), Lower Montane Wet Forest (LMWF), Lower Montane Rain Forest (LMRF), and Premontane Rain Forest (PMRF). 
No recipients of aggression were observed departing from the army ant raids; all moved $<2 \mathrm{~m}$ if displaced. Seven of the raids were attended by migrants. Aggressive interactions occurred at three raids, two with migrants present. None of the aggressive interactions involved migrants.

\section{Resident Birds in the Presence and Absence of Migrants}

The mean number of resident birds at raids was not significantly different during the migrant presence and absence seasons $\left(F_{1,50}=1.21, P\right.$ $=0.28)$. The mean resident flock size was nonsignificantly higher during migrant presence season (Fig. 2A), a pattern contrary to expectations if migrants negatively affected residents.

Migrants attended $60.6 \%$ of Pacific slope raids during the migrant presence season. The mean number of residents at raids with migrants was not significantly different from the mean number at raids without migrants $\left(F_{1,31}=2.55, P=0.12\right)$. The mean resident flock size was non-significantly higher with migrants than without (Fig. 2B), contrary to expectations if migrants negatively affected residents.

Species richness analyses indicated no significant relationships between migrant presence and the number of resident bird species at raids. Species accumulation curves for residents overlapped statistically when comparing migrant presence and absence seasons (Fig. 3A), and when comparing presence season raids with and without migrants (Fig. 3B). There was little evidence for seasonal specialization by resident species, such as might be expected if some residents avoided foraging with migrants. There was high overlap in the species composition of resident bird flocks at raids when comparing migrant presence and absence seasons: the estimated probability of species overlap was 0.93 (Chao-Sorensen bias corrected beta diversity statistic). We observed 29 resident bird species at raids in the migrant presence season and 21 resident bird species at raids in the migrant absence season. Fourteen resident species were seen in both seasons. Species seen in only one season were relatively rare: all single-season species were recorded at $1-4$ raids $(2-10.5 \%$ of raids). This suggests the seasonal differences were mainly because of sampling error rather than avoidance of foraging with migrants by some species.

\section{Guild Differences in Body Size and Foraging Substrate Use}

Migrants were significantly smaller in body size than residents at army ant raids $\left(F_{1,239}=\right.$ $18.53, P<0.001)$. However, there was complete size overlap between the guilds; some resident species were both larger and smaller than the most extreme migrant sizes (Fig. 4A; Table 1). Migrant substrate use differed significantly from resident substrate use: migrants used vegetation more often and pounced less often than residents $\left(\chi_{\mathrm{df}}^{2}=2=21.22, P<0.001\right.$; if pouncing was included in the ground category the guild difference still held: $\chi_{\mathrm{df}=1}^{2}=10.96, P=0.001$; Fig. 4B).

\section{DISCUSSION}

\section{Life Zone Differences in Raid Attendance}

Species composition of bird flocks at army ant raids varied significantly among life zones. Army ant raid attendance by migrants was highest in PMWF on the Pacific slope and lowest on the Atlantic slope. Vallely (2001) similarly noted that "Migrants were generally present only at lower elevation swarms..." on the Pacific slope in the Monteverde area. In contrast, ant-following residents were absent from PMWF and were most abundant at Atlantic slope raids. Our data suggest migrants and ant-following residents co-occur relatively rarely at army ant raids. Data from previous mist netting studies in the Monteverde area gave further evidence these guilds had complementary distributions among life zones in the Monteverde area: migrant mist net captures were highest in life zones where ant-following residents were rare or absent (Young et al. 1998). We suggest life zone variation in relative abundance of these guilds largely explains their relative rates of raid attendance.

Migrants may have distinct habitat requirements from most ant-following residents, leading them to settle and overwinter preferentially in different life zones. Alternatively, ant-following residents could play a role in migrant habitat use by influencing migrant wintering locations. Army ant-following birds are aggressive at raids and can reduce raid attendance by other birds, including migrants (Willis 1966, Willson 2004, Brumfield et al. 2007, Touchton and Smith 2011). Some of the migrants we observed attend raids throughout their wintering geographic ranges (Willis 1966, 1984; Hardy 1974; Greene et al. 1984; Coates-Estrada 

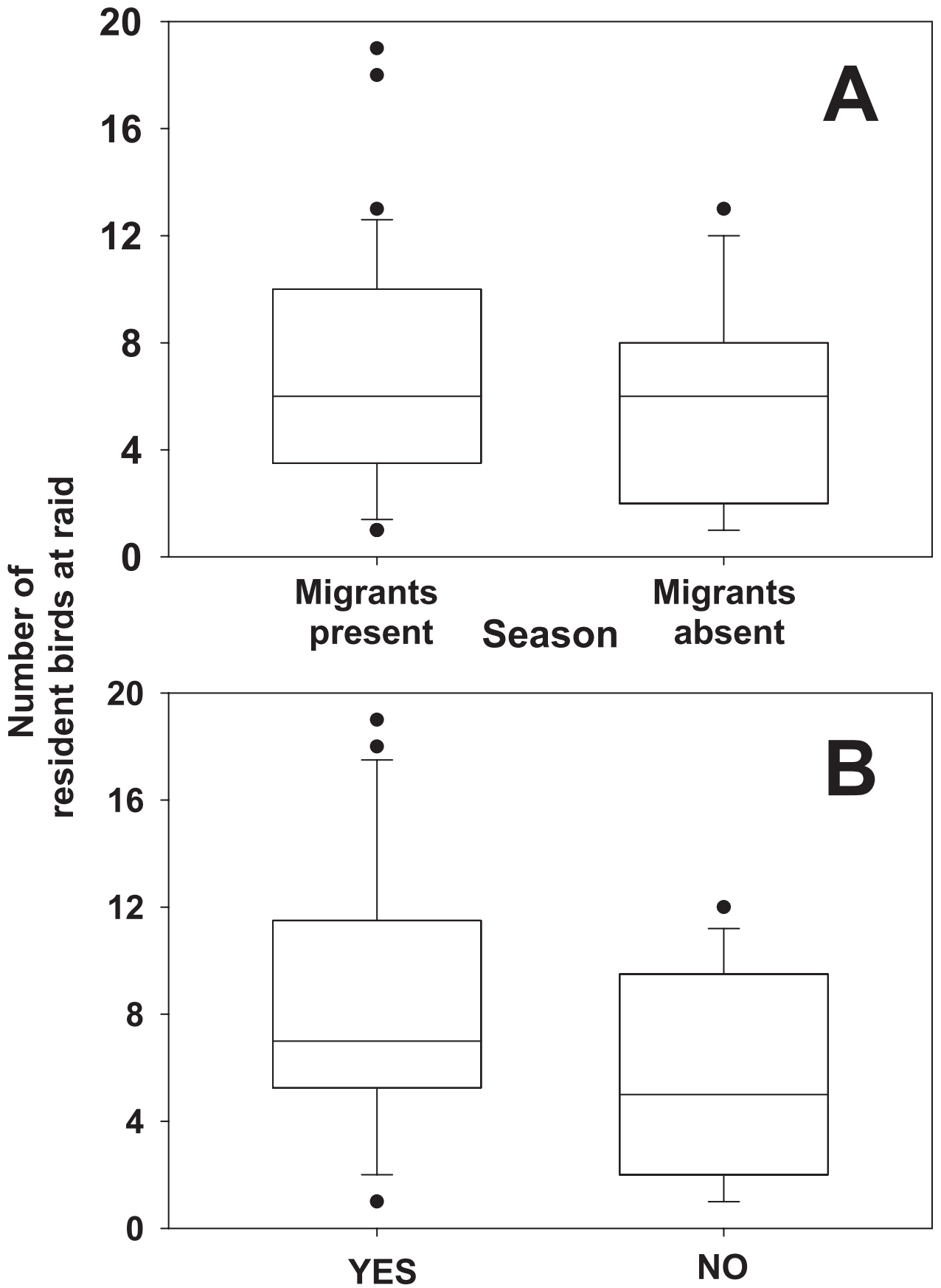

Migrants attending raid

FIG. 2. Box plots of numbers of facultative resident birds in flocks at army ant raids in Costa Rican montane forest (Pacific slope only). Box plots represent medians (central line), interquartiles (boxes), $75 \%$ range (whiskers), and outliers (points). (A) Comparison ofseasons for migrants present and migrants absent. (B) Within the migrants present season, comparison of numbers of facultative resident birds at raids with and without migrants also in attendance. 


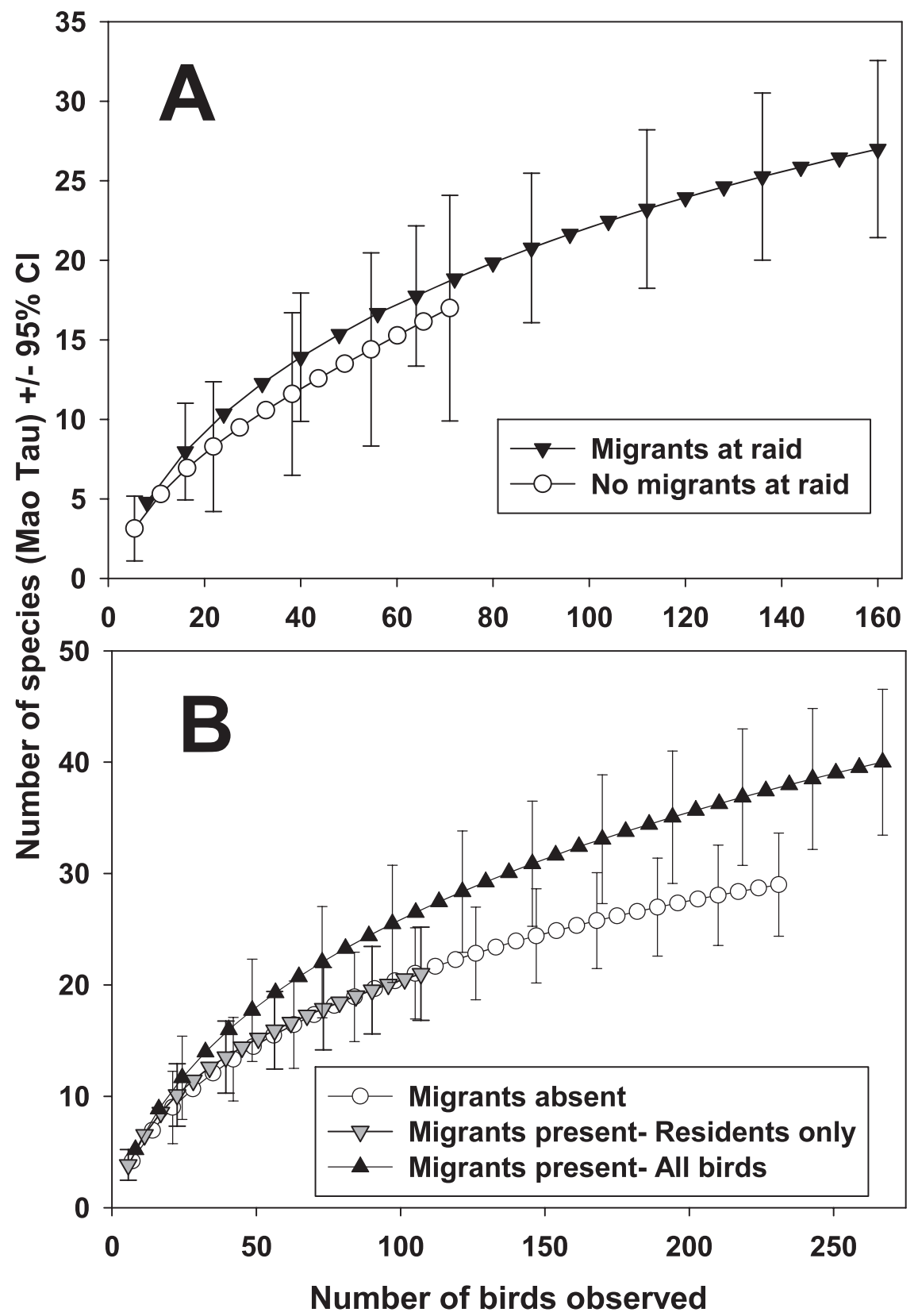

FIG. 3. Species accumulation (rarefaction) curves plotting observed numbers of species (Mao Tau) of birds in different guilds in flocks at army ant raids in Costa Rican montane forest, plotted against sampling effort (number of birds observed, normalized to number of raids observed). Error bars represent $95 \%$ confidence intervals around the observed number of species at a given sampling effort; some error bars are not shown to improve clarity. (A) Seasonal comparison of species richness of resident birds at raids, comparing times of year when migrants are present (wintering) and absent (off-site breeding in North America). A third curve shows total species richness in flocks with migrants included. (B) Within the migrant presence season, comparison of species richness of resident birds at raids with and without migrants also in attendance. 

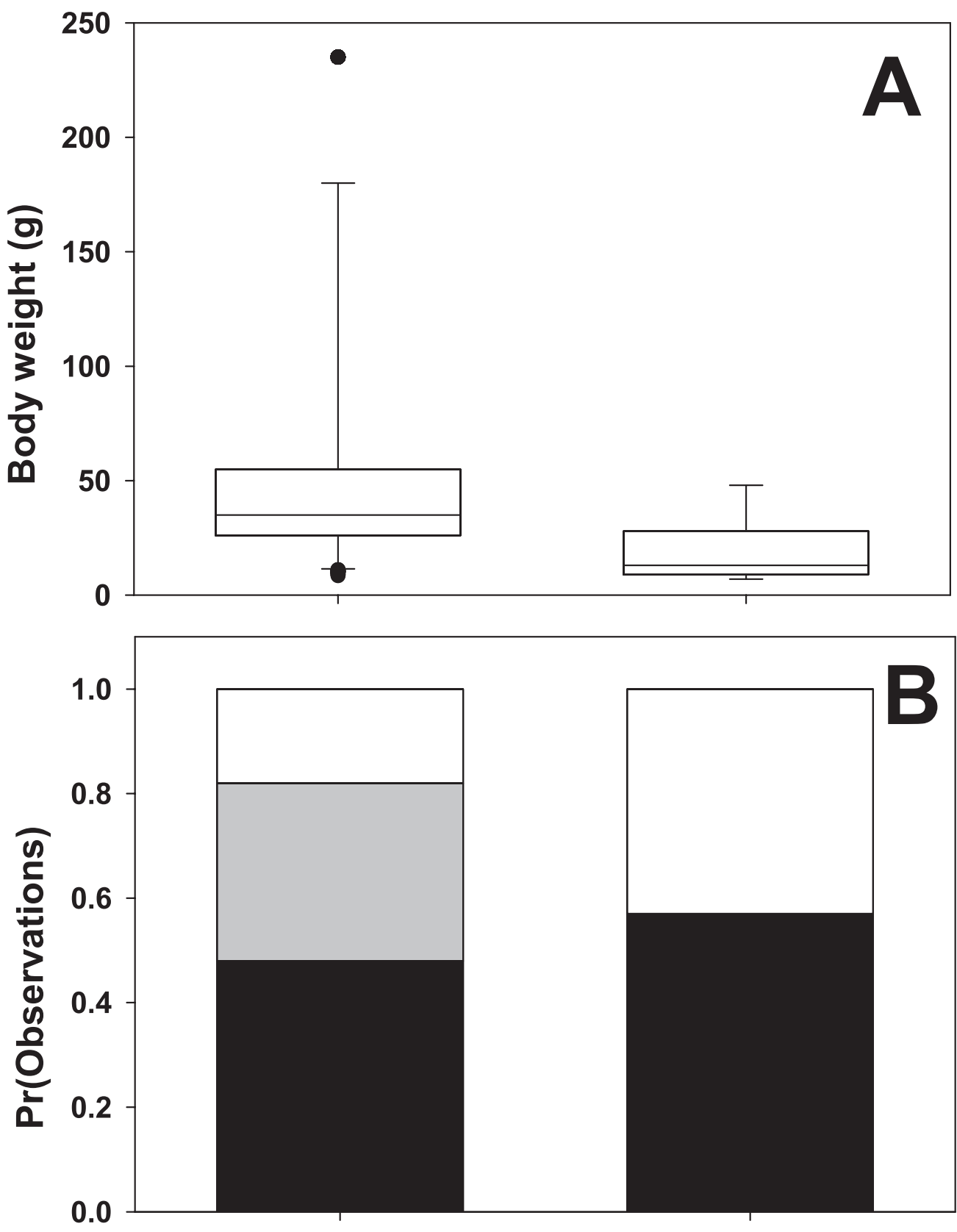

\section{Facultative residents Migrants}

Guild

FIG. 4. Comparisons of body size and foraging substrates between two guilds of birds (facultative residents and migrants) at army ant raids in Costa Rican montane forests. (A) Box plots showing distributions of body weights of all birds observed at raids in Premontane Wet Forest. Box plots represent medians (central line), interquartiles (boxes), 75\% range (whiskers), and outliers (points). (B) Stacked bar graphs representing the proportion of birds in each guild using three foraging substrates (Black: ground; Gray: pounce; White: vegetation). 
and Estrada 1989; Roberts et al. 2000; Meisel 2004; Rios et al. 2008). Army ant raids may be an important wintering food source for these species. Migrants select wintering sites based in part on access to food resources (Johnson et al. 2005, Sherry et al. 2005, Brown and Sherry 2008, Diggs et al. 2011). To the extent that migrants benefit from army ant exploitation, access to foraging opportunities at raids could be a factor that influences landscape variation in migrant abundance. Studies of movement and settlement patterns of naïve first-year migrants in the fall arrival period and observations of army ant raid attendance by first-year birds in areas of overlap with ant-following residents could be used to test this hypothesis.

\section{Low Rates of Aggression at Raids}

Although our sample size was small, our observations in montane forests suggest interspecific aggression at army ant raids was less pronounced than in lowland forests where aggression from ant following birds is an important determinant of avian access to raids (Willson 2004, Brumfield et al. 2007, Touchton and Smith 2011). We did not see evidence for displacement or exclusion of migrants from swarm fronts by resident birds. Green et al. (1984) noted a similar lack of interspecific aggression among birds at army ant raids in montane forest in Mexico.

\section{Resident Raid Attendance With and Without Migrants}

Facultative resident raid attendance was relatively stable across life zones and throughout the year. Migrants had no measureable relationship with resident bird numbers or species richness at raids. Species overlap analyses (Beta diversity statistics) showed little evidence for seasonal changes in the species of resident birds that attended raids.

Migrants attended the majority of raids in the PMWF life zone but did not attend raids without resident birds. Non-significantly higher numbers of resident birds were at raids when migrants attended. These patterns could indicate a slightly higher detectability or attractiveness of larger groups of residents to migrants. Migrants may benefit from exploiting information about army ant raid location and activity from resident birds (Nemeth and Moore 2007, Chaves-Campos 2011, O'Donnell et al. 2012).
The birds we observed were not marked (banded) to permit individual identification. We could not measure individual differences in army ant exploitation behavior. Conspecific wintering migrants can exhibit habitat use differences: migrants can use sedentary or floating behavior in the same wintering location (Brown and Long 2007, Brown and Sherry 2008). Because army ant colonies are mobile, their raids are unpredictable in space and time (Logan et al. 2011, O'Donnell et al. 2012). Floating behavior, and/or shared foraging access to overlapping home ranges, may promote army ant exploitation by wintering migrant birds.

\section{Conclusions}

Taken together, our data show no evidence for inter-guild effects on army ant exploitation between migrants and residents in Central American montane forests. Why did the seasonal addition of migrants to flocks at raids have little effect on resident raid attendants? Migrants may have exploited prey items at raids that would not have been taken by the attending resident birds. As a guild, migrants at raids were distinct from residents: they were on average smaller in size, and differed in foraging substrate by being more arboreal. These guild-level patterns suggest that migrants could, on average, exploit different resources at raids than residents. This would reduce the effect of migrant raid participation on residents, and could partly explain the fact that resident raid attendance did not co-vary with migrant presence. However, there was potential for inter-guild competition between migrants and some resident species, because they overlapped in size and foraging substrate. Some of the most frequent resident raid attendants overlapped with migrants. We did not record the size or identity of individual prey items taken by birds at raids, but prey item specialization seems unlikely for birds foraging at army ant raids (Chesser 1995). We expect there would be near or complete overlap of prey items taken at raids by migrants and residents of similar body size and foraging substrate (Chapman and Rosenberg 1991, Chesser 1995). Do these species compete at raids?

We saw no evidence for interspecific aggression at raids that would indicate interference competition. Furthermore, consistent resident flock composition (numbers of birds, numbers of species, and species identity) with and without migrants does not suggest strong exploitation competition. Previous studies have noted that 
migrants did not affect resident foragers in other contexts, suggesting there are excess food resources that can be exploited by migrants (Johnson et al. 2005, 2006; Randler 2013). Few tropical resident birds breed during migrant presence season, so migrants have minimal potential to impact resident fecundity (Young et al. 1998, Young and MacDonald 2000). Factors other than access to food resources shared with migrants, such as food for nestlings and nest predation, may limit resident population sizes and indirectly provide foraging opportunities for wintering migrants (Johnson et al. 2006).

\section{ACKNOWLEDGMENTS}

Susan Bulova, John Burt, Sara Deleon, Robert Driver, Sarah Faegre, Emily Hollenbeck, Dugan Maynard and Siobhan O'Donnell assisted with observations in the field. Susan Bulova and Sara Deleon reviewed the manuscript and made suggestions for statistical analyses. Three anonymous reviewers made useful comments on the manuscript. Thanks to Frank Joyce and Katy Van Dusen for logistical support in Monteverde, and to residents of the Monteverde area who allowed access to private properties for data collection. The Tropical Science Center, San Luis Ecolodge/University of Georgia, the Monteverde Conservation League, and the Monteverde Institute extended support and access to land for data collection. Research was conducted under permits from the Ministry of the Environment and Energy, Republic of Costa Rica (Scientific Passport numbers 0387 and 01667), and in accordance with the laws of the Republic of Costa Rica. Thanks to the Organization for Tropical Studies (OTS) for research support, including assistance in obtaining permits. This project was supported by an ALCOR Fellowship (University of Washington Psychology) and an OTS Post-Course Award to A.K., and University of Washington Royalty Research Fund, National Geographic/Waitt Foundation, and Drexel University start-up grants to S. O'D.

\section{LITERATURE CITED}

Bensusan, K. J., B. Shorrock, And K. C. Hamer. 2011. Impacts of passage migrant songbirds on behaviour and habitat use of resident Sardinian Warblers Sylvia melanocephala in Gibraltar. Ibis 153:616-621.

Brown, D. R. AND J. A. Long. 2007. What is a winter floater? Causes, consequences, and implications for habitat selection. Condor 109:548-565.

Brown, D. R. AND T. W. ShERry. 2008. Alternative strategies of space use and response to resource change in a wintering migrant songbird. Behavioral Ecology 19:1314-1325.

Brumfield, R. T., J. G. Tello, Z. A. Cheviron, M. D. Carling, N. Crochet, and K. V. Rosenberg. 2007. Phylogenetic conservatism and antiquity of a tropical specialization: army-ant-following in the typical antbirds (Thamnophilidae). Molecular Phylogenetics and Evolution 45:1-13.
Chapman, A. And K. V. Rosenberg. 1991. Diets of four sympatric Amazonian woodcreepers (Dendrocolaptidae). Condor 93:904-915.

Chaves-Campos, J. 2011. Ant colony tracking in the obligate army ant-following antbird Phaenostictus mcleannani. Journal of Ornithology 152:497-504.

Chesser, R. T. 1995. Comparative diets of obligate antfollowing birds at a site in northern Bolivia. Biotropica 27:382-390.

Chipley, R. M. 1976. The impact of wintering migrant wood warblers on resident insectivorous passerines in a subtropical Colombian oak woods. Living Bird 15:119-141.

Coates-EstradA, R. AND A. EstradA. 1989. Avian attendance and foraging at army-ant swarms in the tropical rainforest of Los Tuxtlas, Veracruz, Mexico. Journal of Tropical Ecology 5:281-292.

Colwell, R. K. 2009. EstimateS software: statistical estimation of species richness and shared species from samples. Version 8.2. viceroy.eeb.uconn.edu/estimates/ (accessed January 2012).

Diggs, N. E., P. P. Marra, And R. J. Cooper. 2011. Resource limitation drives patterns of habitat occupancy during the nonbreeding season for an omnivorous songbird. Condor 113:646-654.

Garrigues, R. And R. DEAn. 2007. The birds of Costa Rica. Cornell University Press, Ithaca, New York, USA.

Greene, E. D., D. Wilcove, AND M. McFarland. 1984. Observations of birds at an army ant swarm in Guerrero, Mexico. Condor 86:192-193.

Guindon, C. F. 1997. The importance of forest fragments to the maintenance of regional biodiversity surrounding a tropical montane reserve, Costa Rica. $\mathrm{PhD}$ thesis, Yale University, New Haven, USA.

HABER, W. A. 2000. Plants and vegetation. Pages 39-94 in Monteverde: ecology and conservation of a tropical cloud forest (N. Nadkarni and N. Wheelwright, Editors). Oxford University Press, New York, USA.

HARDY, J. W. 1974. Jays as army ant followers. Condor 76:102-119.

HARPER, L. H. 1989. The persistence of ant-following birds in small Amazonian forest fragments. Acta Amazonica 19:249-263.

HARVEY, C. 2000. Colonization of agricultural windbreaks by forest trees: effects of connectivity and remnant trees. Ecological Applications 10:1762-1773.

HoldRIDGE, L. R. 1966. The life zone system. Adansonia 6:199-203.

JANKowski, J. E., A. L. CieckA, N. Y. Meyer, AND K. N. RABENOLD. 2009. Beta diversity along environmental gradients: implications of habitat specialization in tropical montane landscapes. Journal of Animal Ecology 78:315-327.

Jedlicka, J. A., R. Greenberg, I. Perfecto, S. M. Philpott, And T. V. Dietsch. 2006. Seasonal shift in the foraging niche of a tropical avian resident: resource competition at work? Journal of Tropical Ecology 22:385-395.

Johnson, M. D., T. W. Sherry, A. M. Strong, And A. MEDORI. 2005. Migrants in Neotropical bird commu- 
nities: an assessment of the breeding currency hypothesis. Journal of Animal Ecology 74:333-341.

Johnson, M. D., A. M. Strong, AND T. W. Sherry. 2006. Migrants in tropical bird communities: the balanced breeding limitation hypothesis. Journal of Avian Biology 37:229-237.

KirK, D. A. And J. E. P. Currall. 1994. Habitat associations of migrant and resident vultures in central Venezuela. Journal of Avian Biology 25:327-337.

KronaUeR, D. J. C. 2009. Recent advances in army ant biology (Hymenoptera: Formicidae). Myrmecological News 12:51-65.

Kumar, A. And S. O'Donnell. 2007. Fragmentation and elevation effects on bird-army ant interactions in Neotropical montane forest of Costa Rica. Journal of Tropical Ecology 23:581-590.

LEISLER, B. 1992. Habitat selection and coexistence of migrants and Afrotropical residents. Ibis 134 SI:77-82.

Logan, C. J., S. O’DonNEll, AND N. S. Clayton. 2011. A case of mental time travel in ant-following birds? Behavioral Ecology 22:1149-1153.

Meisel, J. E. 2004. The influence of microclimate and habitat area on the ecology of the army ant Eciton burchelli in tropical forest fragments. $\mathrm{PhD}$ thesis. University of Wisconsin-Madison, Madison, USA.

Moyle, R. G., R. T. Chesser, R. T. Brumfield, J. G. Tello, D. J. Marchesea, and J. Cracraft. 2009. Phylogeny and phylogenetic classification of the antbirds, ovenbirds, woodcreepers, and allies (Aves: Passeriformes: infraorder Furnariides). Cladistics 25: 386-405.

Nakazawa, Y., A. T. Peterson, E. Martinez-Meyer, AND A. G. NAvarroa-Suguenza. 2004. Seasonal niches of Nearctic-Neotropical migratory birds: implications for the evolution of migration. Auk 121:610618.

Nemeth, Z. And F. R. Moore. 2007. Unfamiliar stopover sites and the value of social information during migration. Journal of Ornithology 148(supp. 2):369376.

O’Donnell, S., M. Kaspari, A. Kumar, J. LattKe, and S. POWELL. 2011. Elevational and geographic variation in army ant swarm raid rates. Insectes Sociaux 58:293298.

O’Donnell, S., A. Kumar, And C. Logan. 2010. Army ant raid attendance and bivouac-checking behavior by Neotropical montane forest birds. Wilson Journal of Ornithology 122:503-512.

O'Donnell, S., C. J. Logan, AND N. S. Clayton. 2012. Specializations of birds that attend army ant raids: an ecological approach to cognitive and behavioral studies. Behavioural Processes 91:267-274.

Rabol, J. 1987. Coexistence and competition between overwintering Willow Warblers Phylloscopus trochilus and local warblers at Lake Naivasha, Kenya. Ornis Scandinavica 18:101-121.

RANDLER, C. 2013. Do migrants influence the foraging behaviour of the insectivorous Cyprus Wheatear, Oenanthe cypriaca, at a stopover site? (Aves: Passeriformes). Zoology in the Middle East 59:196202.
REMSEN JR., J. V. AND D. V. Good. 1996. Misuse of data from mist-net captures to assess relative abundance in bird populations. Auk 113:381-398.

Rios, M., G. LONDOÑO, AND L. BIANCUCCI. 2008. Notes on birds that follow army ants in the northern Andes. Ornithologia Neotropical 19:137-142.

Roberts, D. L., R. J. CoOPer, ANd L. J. Petit. 2000. Flock characteristics of ant-following birds in premontane moist forest and coffee agroecosystems. Ecological Applications 10:1414-1425.

Salewski, V., B. Almasi, A. Heuman, M. Thoma, And A. SCHLAGETER. 2007. Agonistic behaviour of Palaearctic passerine migrants at a stopover site suggests interference competition. Ostrich 78:349-355.

SAlewski, V., F. BAirlein, AND B. Leisler. 2003. Niche partitioning • of two Palearctic passerine migrants with Afrotropical residents in their West African winter quarters. Behavioral Ecology 14:493-502.

Sherry, T. W., M. D. Johnson, AND A. M. Strong. 2005. Does winter food limit populations of migratory birds? Pages 414-425 in Birds of two worlds (R. Greenberg and P. P. Marra, Editors). Johns Hopkins University Press, Baltimore, USA.

Sridhar, H., U. SRINIVASAN, R. A. Askins, J. C. CANAlesDelgadillo, ET AL. 2012. Positive relationships between association strength and phenotypic similarity characterize the assembly of mixed-species bird flocks worldwide. American Naturalist 180:777-790.

Stiles, F. G. And A. F. Skutch. 1989. A guide to the birds of Costa Rica. Cornell University Press, Ithaca, New York, USA.

SwARTZ, M. B. 2001. Bivouac checking, a novel behavior distinguishing obligate from opportunistic species of army-ant following birds. Condor 103:629-633.

Touchton, J. M. AND J. N. M. Smith. 2011. Species loss, delayed numerical responses, and functional compensation in an antbird guild. Ecology 92:1126-1136.

VALLELY, A. C. 2001. Foraging at army ant swarms by fifty bird species in the highlands of Costa Rica. Ornithologia Neotropical 12:271-275.

WiLLIs, E. O. 1966. The role of migrant birds at swarms of army ants. Living Bird 5:187-231.

Willis, E. O. 1972. The behavior of Plain-brown Woodcreepers Dendrocincla fuliginosa. Wilson Bulletin 84:377-420.

WILLIS, E. O. 1984. Neotropical thrushes (Turdidae) as army ant followers. Ciencia e Cultura 36:1197-202.

Willis, E. O. AND Y. ONIKI. 1978. Birds and army ants. Annual Review of Ecology and Systematics 9:243263.

WILLSON, S. K. 2004. Obligate army-ant-following birds: a study of ecology, spatial movement patterns, and behavior in Amazonian Peru. Ornithological Monographs 55:1-67.

Wrege, P. H., M. Wikelski, J. T. Mandel, T. RassweiLER, AND I. D. COUZIN. 2005. Antbirds parasitize foraging army ants. Ecology 86:555-559.

Young, B. E. AND D. B. Macdonald. 2000. Birds. Pages 179-222 in Monteverde: ecology and conservation of a tropical cloud forest (N. Nadkarni and N. Wheel- 
wright, Editors). Oxford University Press, New York, USA.

Young, B. E., D. Derosier, And G. V. N. Powell. 1998. Diversity and conservation of understory birds in the Tilarán Mountains, Costa Rica. Auk 115:998-1016.
ZIMMER, K. J. AND M. L. ISLER. 2003. Family Thamnophilidae (Antbirds). Pages 448-681 in Handbook of the birds of the world. Volume 8 (J. Del Hoyo, A. Elliott, and D. Christie, Editors). Lynx Edicions, Barcelona, Spain. 